JPE 10-5-11

\title{
Stand-Alone Wind Energy Conversion System with an Asynchronous Generator
}

\author{
Bhim Singh* and Shailendra Sharma $^{\dagger}$ \\ $\dagger *$ Dept. of Electrical Engineering, Indian Institute of Technology, Delhi, India
}

\begin{abstract}
This paper deals with a stand-alone wind energy conversion system (WECS) with an isolated asynchronous generator (IAG) and voltage and frequency (VF) control feeding three-phase four-wire loads. The reference generator currents are estimated using the instantaneous symmetrical component theory to control the voltage and frequency of an IAG system. A three-leg voltage source converter (VSC) with an isolated star/delta transformer is used as an integrated VSC. An integrated VSC with a battery energy storage system (BESS) is used to control the active and reactive powers of the WECS. The WECS is modeled and simulated in MATLAB using the Simulink and the Sim Power System (SPS) toolboxes. The proposed VF controller functions as a voltage and frequency regulator, a load leveler, a load balancer and a harmonic eliminator in the WECS. A comparison is made on the rating of the VSC with and without ac capacitors connected at the terminals of an IAG. Simulation and test results are presented to verify the control algorithm.
\end{abstract}

Key Words: Asynchronous Generator, Battery, Frequency Control, Transformers, Voltage Control, Wind Energy

\section{INTRODUCTION}

Wind energy is the fastest growing and most widely utilized emerging renewable energy technologies in electrical energy conversion systems at present. However, the majority of wind energy resources are still untapped, while the potential for energy from wind generation is vast. Wind turbine generators (WTGs) can be classified into two basic categories, i.e. fixed speed and variable speed. Fixed speed wind turbines are electrically quite simple devices consisting of an aero-dynamic rotor driving a low speed shaft, a gear box, a high speed shaft and a generator. In stand-alone power generation, a fixedspeed WTG with an isolated asynchronous generator (IAG) and a battery energy storage system (BESS) is one of the most promising options [1]. The BESS can satisfy the technical requirements for primary frequency regulation by absorbing the active power from the generator bus for high frequency periods, above a nominal value, and injecting active power to the bus during low frequency excursions, below a nominal set point [2].

However, substantial literature is available on stand-alone power generation with IAGs [3-7]. In [3], the authors have discussed the voltage and frequency regulation of standalone power generation based on a capacitor excited IAG for three-phase four-wire consumer loads. Voltage regulation is achieved using a static compensator (STATCOM) control while frequency regulation is achieved by controlling the

\footnotetext{
Manuscript received Apr. 19, 2010; revised Jul. 16, 2010

$\dagger$ Corresponding Author: ssharma.iitd@gmail.com

Tel: +91-011-2659-1045, Fax: +91-011-2658-1606, IITD

* Electrical Engineering Department, IIT, India
}

electronic load controller. This scheme has been implemented as a constant power prime-mover based power generation system. Kasal et al [5] have presented a voltage and frequency controller for a three-phase four-wire autonomous wind energy conversion system (WECS) with a capacitor excited IAG. A star/delta tertiary winding transformer has been used with a voltage source converter (VSC) and a BESS for voltage and frequency regulation. In [7], the authors have used three single phase transformers, three single phase VSCs and a BESS for the voltage and frequency regulation. However, three single phase transformers and four switches in each VSC inherently increase the size and complexity of the controller.

In this paper, a new control algorithm is proposed for a VFC with a star-delta connected transformer, three-leg VSC and a BESS for three-phase four-wire consumer loads in a stand-alone IAG-based WECS. The proposed control scheme is based on the instantaneous symmetrical component theory [8]. The proposed controller has the bi-directional capability of active and reactive power flows and it regulates the rated terminal voltage and frequency of an IAG along with a load leveler, a load balancer, a neutral current compensator and a harmonic eliminator.

\section{System CONFiguration AND THE PRINCIPLE OF OPERATION}

Fig. 1 shows a schematic diagram of the proposed VFC along with an IAG and consumer loads. A three-leg VSC along with a BESS is connected at the point of common coupling (PCC) through a star-delta transformer. The consumer loads are also connected at the PCC. The neutral terminal for 


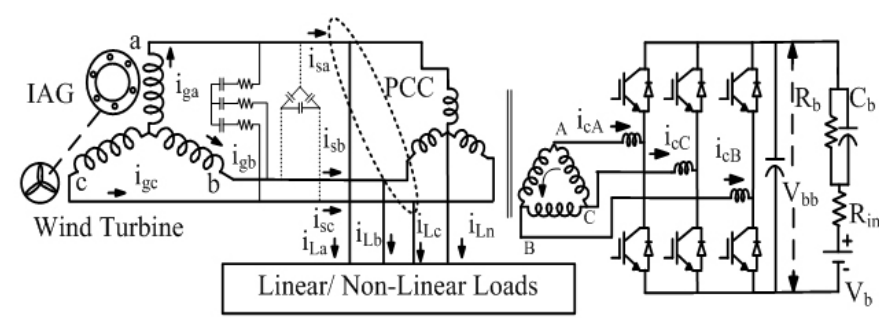

Fig. 1. Schematic diagram of proposed VFC.

the loads is created through a star terminal of the star-delta transformer.

The operating principle of the VFC is based on the control of the reactive power component of the generator currents to regulate the rated terminal voltage at the PCC, and the control of the active power component of the generator current for keeping the generator frequency constant irrespective of variations in wind speed and load. It provides the function of a load leveler with a BESS by absorbing the additional generated active power during high wind speeds or at partial loadings. The VFC also serves as a load balancer under unbalanced loading by circulating the zero sequence current through the star-delta transformer. As a harmonics eliminator, the VSC of the VFC supplies the oscillating component of the instantaneous active and reactive powers of the consumer loads.

\section{Control Strategy}

As shown in Fig. 2, the control strategy of the proposed VFC is realized using the extraction of the reference generator currents. The reference generator currents are extracted using the instantaneous symmetrical component theory (ISCT). For estimation of the reference generator active power, the filtered average (dc) power drawn by the customer loads is subtracted from the output of the frequency PI (Proportional-Integral) controller. To regulate the rated terminal voltage, the IAG requires reactive power support. Therefore there must be a phase difference between the generator voltage and the generator current to regulate the terminal voltage. The desired power factor angle $(\beta)$ of the generator current is extracted from the output of the terminal voltage PI controller. The active power component of each phase of the generator current is extracted using the product of the same phase voltage, the reference generator power and the amplitude of the three phase terminal voltages. Similarly, the reactive power component of each phase of the generator current is estimated using the product of the vector difference of the other phase voltages, the power factor angle and the amplitude of the three-phase terminal voltages. The reference generator current is the vector sum of the active and reactive power component of the generator current.

The basic equations of the VFC are as follows:

\section{A. Estimation of the Phase Voltages}

The line voltages $v_{a b}$ and $v_{b c}$ are sensed and the phase voltages $v_{a}, v_{b}$ and $v_{c}$ are estimated as [9].

$$
\left[\begin{array}{l}
v_{a} \\
v_{b} \\
v_{c}
\end{array}\right]=\frac{1}{3}\left[\begin{array}{cc}
2 & 1 \\
-1 & 1 \\
-1 & -2
\end{array}\right]\left[\begin{array}{l}
v_{a b} \\
v_{b c}
\end{array}\right] .
$$

The sensed voltage may have instantaneous positive, negative and zero sequence components. Let us say that for a phase ' $\mathrm{a}$ ' these components are represented as $V_{a}^{+}(t), V_{a}^{-}(t)$ and $V_{a}^{0}(t)$ and can be expressed in terms of the symmetrical components as follows [8]:

$$
\left[\begin{array}{c}
V_{a}^{0} \\
V_{a}^{+} \\
V_{a}^{-}
\end{array}\right]=\frac{1}{3}\left[\begin{array}{ccc}
1 & 1 & 1 \\
1 & a & a^{2} \\
1 & a^{2} & a
\end{array}\right]\left[\begin{array}{c}
v_{a}(t) \\
v_{b}(t) \\
v_{c}(t)
\end{array}\right]
$$

where $a$ is the complex operator equal to $e^{j 2 \pi / 3}$. In the proposed control scheme it is desired that the generated voltage have only an instantaneous positive sequence component.

Similarly the load current for phase 'a' can be decomposed in to positive, negative and zero sequence components as $I_{L a}^{+}(t), I_{L a}^{-}(t)$ and $I_{L a}^{0}(t)$ respectively and can be expressed as:

$$
\left[\begin{array}{c}
I_{a}^{0} \\
I_{a}^{+} \\
I_{a}^{-}
\end{array}\right]=\frac{1}{3}\left[\begin{array}{ccc}
1 & 1 & 1 \\
1 & a & a^{2} \\
1 & a^{2} & a
\end{array}\right]\left[\begin{array}{c}
i_{a}(t) \\
i_{b}(t) \\
i_{c}(t)
\end{array}\right]
$$

\section{B. Extractions of the Three-Phase Reference Generator Cur- rents}

The three-phase reference generator currents are estimated using the instantaneous symmetrical component theory [8]. For the extraction of three-phase generator currents three basic conditions must be satisfied. The first condition is that there should not be any zero sequence components in generator currents, and generator currents are balanced as:

$$
i_{g a}+i_{g b}+i_{g c}=0 .
$$

The second condition is that the reactive power delivered from the generator should be controlled by the phase angle $(\Phi+)$ between the positive sequence phase voltage vector $\left\{V^{+}(t)\right\}$ and the generator phase current vector $\left\{I_{g}^{+}(t)\right\}$ for voltage regulation of the generator bus as:

$$
\angle V^{+}(t)=\angle\left\{I_{g}^{+}(t)\right\}+\phi^{+}
$$

where:

$$
\begin{aligned}
I_{g}^{+}(t) & =I_{g a}(t)+a I_{g b}(t)+a^{2} I_{g c}(t) \\
V^{+}(t) & =V_{a}(t)+a V_{b}(t)+a^{2} V_{c}(t),
\end{aligned}
$$

This implies that:

$$
\begin{aligned}
& \angle\left\{V_{a}(t)+a V_{b}(t)+a^{2} V_{c}(t)\right\} \\
= & \angle\left\{I_{a}(t)+a I_{b}(t)+a^{2} I_{b}(t)\right\}+\phi^{+} .
\end{aligned}
$$

Eq. (6) can be simplified by substituting the values of $a$ and $a^{2}$ as:

$$
\begin{aligned}
& \angle\left\{\left(v_{a}-\frac{1}{2} v_{b}-\frac{1}{2} v_{c}\right)+j \frac{\sqrt{3}}{2}\left(v_{b}-v_{c}\right)\right\} \\
= & \angle\left\{\left(i_{g a}-\frac{1}{2} i_{g b}-\frac{1}{2} i_{g c}\right)+j \frac{\sqrt{3}}{2}\left(i_{g b}-i_{g c}\right)\right\}+\phi^{+} .
\end{aligned}
$$


Equating the angles, one can simplify Eq. (7) as:

$$
\tan ^{-1}\left(X_{1} / X_{2}\right)=\tan ^{-1}\left(X_{3} / X_{4}\right)+\Phi^{+}
$$

where $X_{1}, X_{2}, X_{3}$ and $X_{4}$ are defined as:

$$
\begin{aligned}
& X_{1}=\frac{\sqrt{3}}{2}\left(v_{b}-v_{c}\right), \quad X_{2}=v_{a}-\frac{1}{2} v_{b}-\frac{1}{2} v_{c}, \\
& X_{3}=\frac{\sqrt{3}}{2}\left(i_{g b}-i_{g c}\right), \text { and } X_{4}=i_{g a}-\frac{1}{2} i_{g b}-\frac{1}{2} i_{g c} \\
& \tan (x+y)=\frac{\tan x+\tan y}{1-\tan x \tan y}
\end{aligned}
$$

Eq. (8) can be expanded as:

$$
\frac{X_{1}}{X_{2}}=\tan \left\{\tan ^{-1}\left(X_{3} / X_{4}\right)+\varphi^{+}\right\}=\frac{\left(X_{3} / X_{4}\right)+\tan \phi^{+}}{1-\left(X_{3} / X_{4}\right) \tan \phi^{+}} \text {. }
$$

Solving Eq. (9) leads to:

$\left(v_{b}-v_{v}-3 \psi v_{a}\right) i_{g a}+\left(v_{c}-v_{a}-3 \psi v_{b}\right) i_{g b}+\left(v_{a}-v_{b}-3 \psi v_{c}\right) i_{g c}$

where $\psi=\left(\tan \Phi^{+} / \sqrt{3}\right) . \Phi^{+}$is the phase angle between the positive sequence generator voltage and the current.

The third condition states that the generator should supply only the average power $\left(P_{g}\right)$, i.e.:

$$
v_{a} i_{g a}+v_{b} i_{g b}+v_{c} i_{g c}=P_{g} .
$$

Simplifying eqns. (3), (10) and (11) leads to the extraction of the reference three-phase generator currents as:

$$
\begin{aligned}
i_{g a}^{*} & =(3 / 2)\left[\left\{v_{a}-\left(v_{b}-v_{c}\right) \psi\right\}\left(P_{g}^{*}\right) / V_{t}^{2}\right] \\
& =A\left[\left\{v_{a}-\left(v_{b}-v_{c}\right) \psi\right\}\left(P_{g}^{*}\right)\right] \\
i_{g b}^{*} & =(3 / 2)\left[\left\{v_{b}-\left(v_{c}-v_{a}\right) \psi\right\}\left(P_{g}^{*}\right) / V_{t}^{2}\right] \\
& =A\left[\left\{v_{b}-\left(v_{c}-v_{a}\right) \psi\right\}\left(P_{g}^{*}\right)\right] \\
i_{g c}^{*} & =(3 / 2)\left[\left\{v_{c}-\left(v_{a}-v_{b}\right) \psi\right\}\left(P_{g}^{*}\right) / V_{t}^{2}\right] \\
& =A\left[\left\{v_{c}-\left(v_{a}-v_{b}\right) \psi\right\}\left(P_{g}^{*}\right)\right]
\end{aligned}
$$

where $V_{t}=\sqrt{2\left(v_{a}^{2}+v_{b}^{2}+v_{c}^{2}\right) / 3}$ and $A=\left(3 / 2 V_{t}^{2}\right)$

\section{Estimation of the Reference Positive Sequence Phase Angle}

The reference positive sequence phase angle (PSPA) $\Phi+$ between the generator voltage and its current depends on the generator bus terminal voltage which further depends on the excitation needs of the IAG, the load on the generator bus and the prime-mover speed. Therefore a proportional-integral (PI) controller is used to estimate the PSPA. The ac voltage error at the nth sampling instant is as:

$$
V_{e}(n)=V_{t r}(n)-V_{t}(n)
$$

where $V_{t r}(n)$ is the amplitude of the reference ac terminal phase voltage and $V_{t}(n)$ is the amplitude of the sensed three phase ac voltage at the terminals of an asynchronous generator at the nth sampling instant given in eqn. (10).

The output of the voltage PI controller at the $n$th sampling instant is expressed as:

$$
\phi^{+}(n)=\phi^{+}(n-1)+k_{p a}\left\{V_{e}(n)-V_{e}(n-1)\right\}+k_{i a} V_{e}(n)
$$

where $k_{p a}$ and $k_{i a}$ are the proportional and integral gain constants of the PI controller. $V_{e}(n)$ and $V_{e}(n-1)$ are the voltage

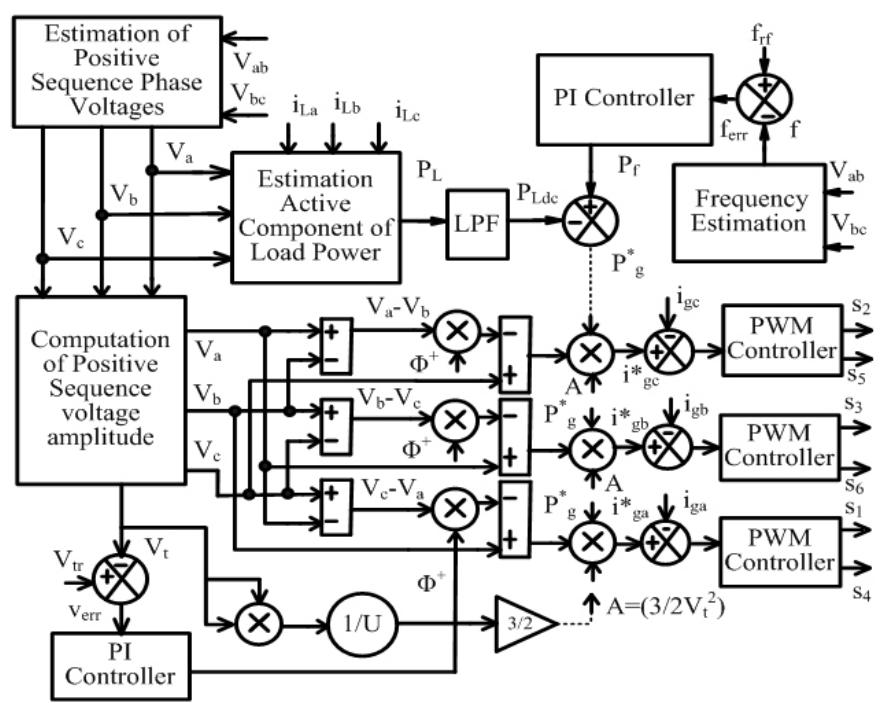

Fig. 2. Proposed Control Scheme of VFC in WECS.

errors in the nth and $(n-1)$ th sampling instants, $\Phi^{+}(n)$ and $\Phi^{+}(n-1)$ are the outputs of the voltage PI controller in the $n$th and $(n-1)$ th instants needed for voltage control. The computed PSPA $\Phi^{+}$is used in $\psi=\left(\tan \Phi^{+} / \sqrt{3}\right)$. This $\psi$ is used in eq. (12) for estimation of the reference generator currents.

\section{Estimation of the Reference Generator Power}

The algebraic difference between the output of the frequency PI controller $\left(P_{f}\right)$ and the extracted average (dc component) load power $\left(P_{L d c}\right)$ provides the reference generator power $\left(P_{g}^{*}\right)$. The load power is computed as:

$$
\begin{gathered}
P_{L}=v_{a} i_{L a}+v_{b} i_{L b}+v_{c} i_{L c} \\
P_{L}=P_{L a c}+P_{L d c} .
\end{gathered}
$$

This load power consists of an average (dc component) $P_{L d c}$ and an oscillating component $\left(P_{L a c}\right)$. It is desired that the dc component be supplied by the generator. Therefore to extract the dc component of the load power $\left(P_{L d c}\right)$ to be supplied by the generator, a second order low pass filter (LPF) is used.

The frequency error is defined as:

$$
f_{e}(n)=f_{r f}(n)-f(n)
$$

where $f_{r f}(n)$ is the reference frequency (i.e. $50 \mathrm{~Hz}$ in this case) and " $f$ " is the frequency of the terminal voltage of an IAG. The instantaneous value of " $f$ " is estimated using a phase locked loop (PLL) [10].

At the $n$th sampling instant, the output of the frequency PI controller is as:

$$
P_{f}(n)=P_{f}(n-1)+k_{p f}\left[f_{e}(n)-f_{e}(n-1)\right]+k_{i f} f_{e}(n) .
$$

The reference active power of the IAG is as:

$$
P_{g}^{*}(n)=P_{f}(n)-P_{L d c}(n) .
$$

The estimated reference generator average power is used in Eq. (12) for estimation of the reference generator currents. 


\section{Matlab Based Modeling}

The MATLAB based simulation model of the proposed IAG system consists of a mechanical system, an electrical system, the proposed VFC and consumer loads. The simulation is carried out on MATLAB version 7.3 using the Sim Power System (SPS) toolbox and the discrete step solver. A detailed modeling description of each part is given in the following sections.

\section{A. Modeling of the Mechanical System}

The mechanical power generated by a wind turbine in a per unit system is given as:

$$
P_{m p u}=0.5 \rho A c_{p p u} v_{w i n d p u}^{3}
$$

where $P_{m p u}$ is the power in a per unit of the nominal power for a particular value of a specific density of air $(\rho)$ and the swept area of the blades (A). $C_{p p u}$ is the performance coefficient in a per unit of the maximum value of the power coefficient. $v_{\text {windpu }}$ is the wind speed in a per unit of the base wind speed. The base wind speed is the mean value of the expected wind speed in $\mathrm{m} / \mathrm{s}$.

To generate a constant frequency, ideally the additional generated power with the increased wind speed is stored into the battery and the speed of the generator is kept almost constant. A generic equation is used to model the wind turbine $C_{p}(\lambda, \beta)$. The equation, based on the turbine characteristics, is as:

$$
\begin{gathered}
C_{p}(\lambda, \beta)=C_{1}\left\{\left(c_{2} / \lambda_{1}\right)-C_{3}-C_{4}\right\} e^{C_{5} / \lambda_{1}}+C_{6} \lambda \\
\left(1 / \lambda_{i}\right)=\left\{1 /\left(\lambda-C_{7} \beta\right)\right\}-\left\{C_{8} /\left(\beta^{3}+1\right)\right\} .
\end{gathered}
$$

In the present model $\beta=0$. An available model of the wind turbine in a per unit system is used to realize the wind power of the WECS.

\section{B. Modeling of the VFC}

The proposed VFC is based on a three-leg VSC and a star/delta transformer with a battery at its dc bus. The midpoint of each leg of the VSC is connected to the secondary windings of a star/delta transformer through the interface inductor. The star terminal of the primary windings of the transformer provides the neutral terminal for three-phase fourwire consumer loads, which leads to a path for the zerosequence load currents without stressing the VSC devices. Further, the proper selection of a transformer turn ratio provides flexibility in optimizing the device rating. The terminal voltage of the battery is given as follows:

$$
V_{b b} \geq(2 \sqrt{2} / \sqrt{3}) V_{L L}
$$

where $V_{L L}$ is the line rms voltage of the secondary windings of the star/delta transformer. Since the battery is an energy storage unit, its energy is represented in kilowatt-hours ( $\mathrm{kWh}$ ), When a capacitor is used to model the battery unit, its capacitance $\mathrm{Cb}$ can be determined as follows [11]:

$$
C_{b}=\frac{k W h * 3600 * 10^{3}}{0.5\left(v_{0 c \max }^{2}-v_{o c \min }^{2}\right)}
$$

where $v_{\text {ocmax }}$ and $v_{\text {ocmin }}$ are the maximum and minimum open circuit voltages of the battery under the fully charged and fully discharged conditions. In the equivalent circuit model, as shown in Fig. $1, R_{i n}$ is the equivalent series resistance of the parallel/series combination of a battery, which is usually a small value. The parallel circuit of $C_{b}$ and $R_{b}$ is used to represent the stored energy and the resistance responsible for self discharging.

\section{Modeling of the RC Ripple Filter}

A first order high pass filter (HPF) is used to filter out the high frequency switching ripples from the voltage at the PCC. The time constant of the filter should be less than the fundamental time period i.e. $20 \mathrm{~ms}$. Therefore, a capacitor of $5 \mu F$ in series with a resistance of $5 \Omega$ is used. It offers an impedance less than $8.09 \Omega$ for the harmonic voltage of a frequency higher than $5 \mathrm{kHz}$. However at the fundamental frequency voltage an impedance of $636.64 \Omega$ is offered for this HPF.

\section{Matlab Based Simulation}

The proposed VFC along with a fixed pitched wind turbine driven IAG is tested with balanced/unbalanced, linear/ nonlinear three-phase four-wire loads. The performance of the VFC is presented under dynamic conditions to validate the control algorithm. A comparison is made to evaluate the differences in the VSC ratings with and without ac capacitors connected at the terminals of an IAG system. A set of results shows the performance under a drop in wind speed and balanced linear consumer loads, in Figs. 3-4. Another set of results shows the performance under an increase in the wind speed and balanced linear consumer loads, in Figs. 5-6. The performance of the VFC is tested with a lagging power factor (pf), balanced/unbalanced linear loads and a fixed wind speed, in Figs. 7-8. In Figs. 9-10, the performance of the VFC is tested with balanced/unbalanced non-linear consumer loads at a fixed wind speed. The waveforms of the generator voltage $\left(V_{a b c}\right)$, the generator current $\left(i_{g a b c}\right)$, the capacitor currents $\left(i_{c a b c}\right)$, the source currents $\left(i_{s a b c}\right)$, the load currents for the three phases $\left(i_{L a}\right),\left(i_{L b}\right)$ and $\left(i_{L c}\right)$, the star-delta transformer primary currents $\left(i_{T a b c}\right)$, the frequency (f), the load neutral current $\left(i_{L n}\right)$, the terminal voltage $\left(V_{t}\right)$, the wind speed $\left(V_{w}\right)$, the instantaneous active power transfer through the generator $\left(P_{g}\right)$, the load $\left(P_{L}\right)$ and the filtered battery charging/discharging power $\left(P_{b}\right)$ are shown during dynamic conditions.

\section{A. Performance of the VFC under Varying Wind Speed with a Balanced Linear Consumer load}

Fig. 3 demonstrates the performance of the VFC with an ac capacitor connected at the terminals of an IAG under a fall in wind speed. Till $2.35 \mathrm{~s}$, the wind speed is $12 \mathrm{~m} / \mathrm{s}$, and the three phase balanced $7.5 \mathrm{~kW}, 0.94 \mathrm{pf}$ lagging load is connected at the generator terminals. The load demand is met through the generator and the battery is in the floating state. At $2.35 \mathrm{~s}$, the wind speed is decreased to $8 \mathrm{~m} / \mathrm{s}$ and the generated 


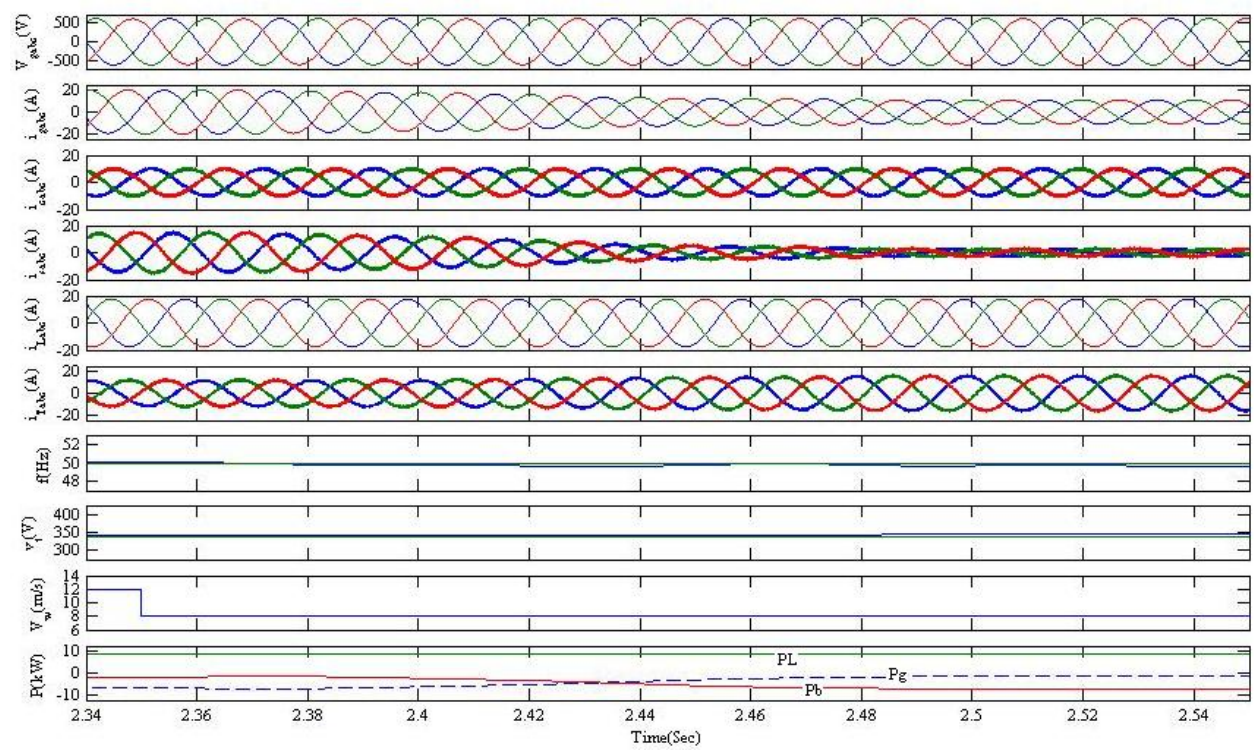

Fig. 3. Performance of VFC with ac capacitors at the terminals of an IAG under fall in wind speed at fixed balanced loads.

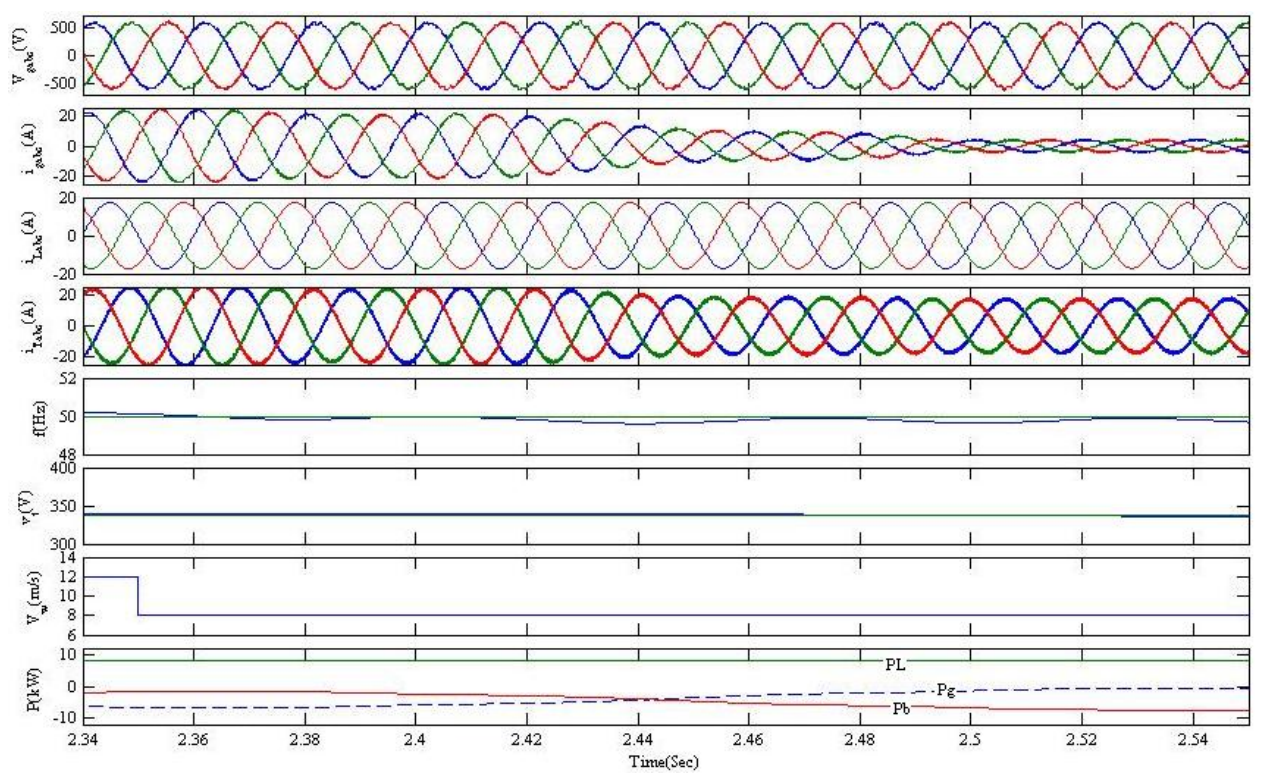

Fig. 4. Performance of VFC without ac capacitors at the terminals of an IAG under fall in wind speed at fixed balanced loads.

power reduces to a low level. With the action of a frequency PI controller, the deficit load power is supplied from the battery, keeping the frequency at a set value of $50 \mathrm{~Hz}$. Fig. 4 shows the performance of the VFC under similar conditions when the VSC is used to supply the reactive power to the IAG, to maintain the rated terminal voltage while no capacitor bank is used for the IAG excitation. It is observed form Figs. 34 , that the voltage and frequency are almost constant during both conditions. However, the VSC ratings are higher when excitation capacitors are not used. The difference in the VSC rating is observed and is shown in the Appendix.

Fig. 5 shows the performance of the VFC with the ac capacitors connected at the terminals of an IAG under an increase in the wind speed. Till $2.7 \mathrm{~s}$, the wind speed is $8 \mathrm{~m} / \mathrm{s}$ and the generated power is very low. During this period, the battery is supplies the deficit power. At $2.7 \mathrm{~s}$, the wind speed increases to $12 \mathrm{~m} / \mathrm{s}$ and there is a rated power generation. The consumer loads are now supplied from the generator and the battery is again in the floating state. If consumer loads are less than the generated power, the difference of the generated power and the load power is utilized in charging the battery. Fig. 6 validates the above statement when the reactive power for the IAG is supplied from the VSC and no ac capacitors are connected at the generator bus.

\section{B. Performance of the VFC with Balanced/unbalanced Linear Loads}

Fig. 7 shows the performance of the VFC with balanced/ unbalanced linear loads and ac capacitors with an IAG at a 


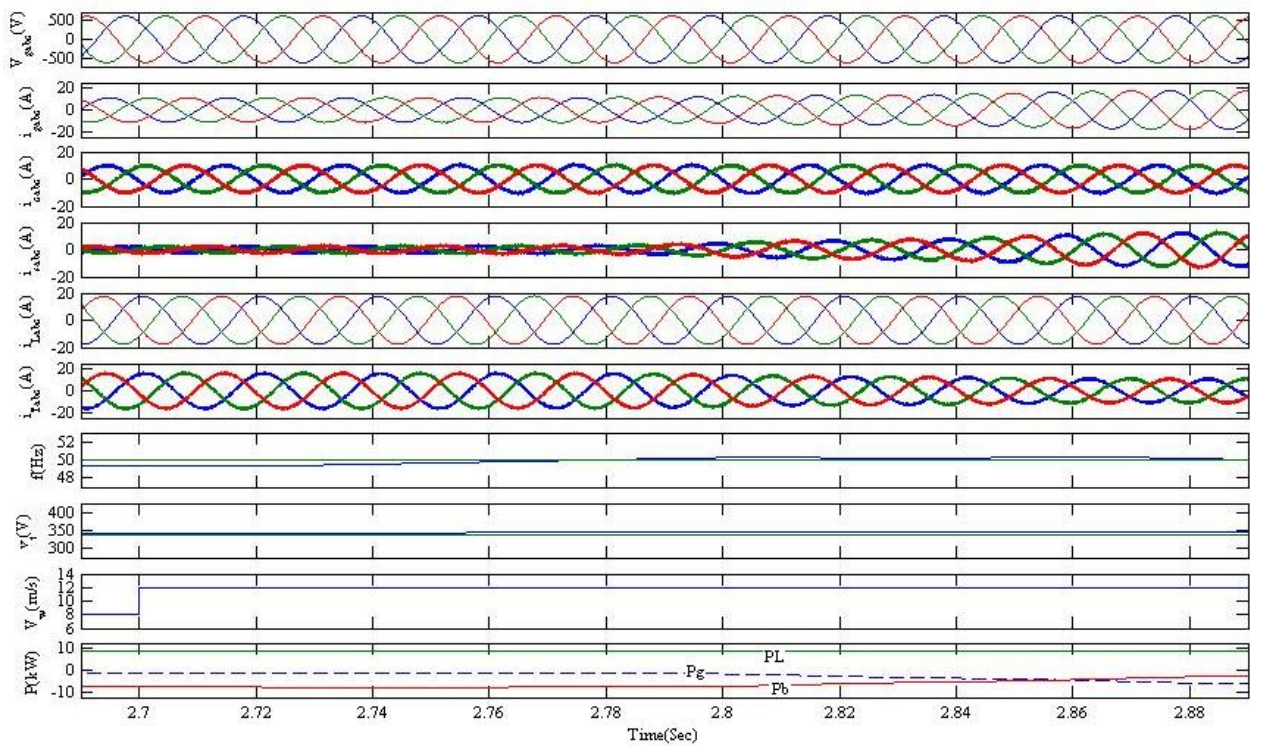

Fig. 5. Performance of VFC with ac capacitors at the terminals of an IAG under increase in wind speed at fixed balanced loads.

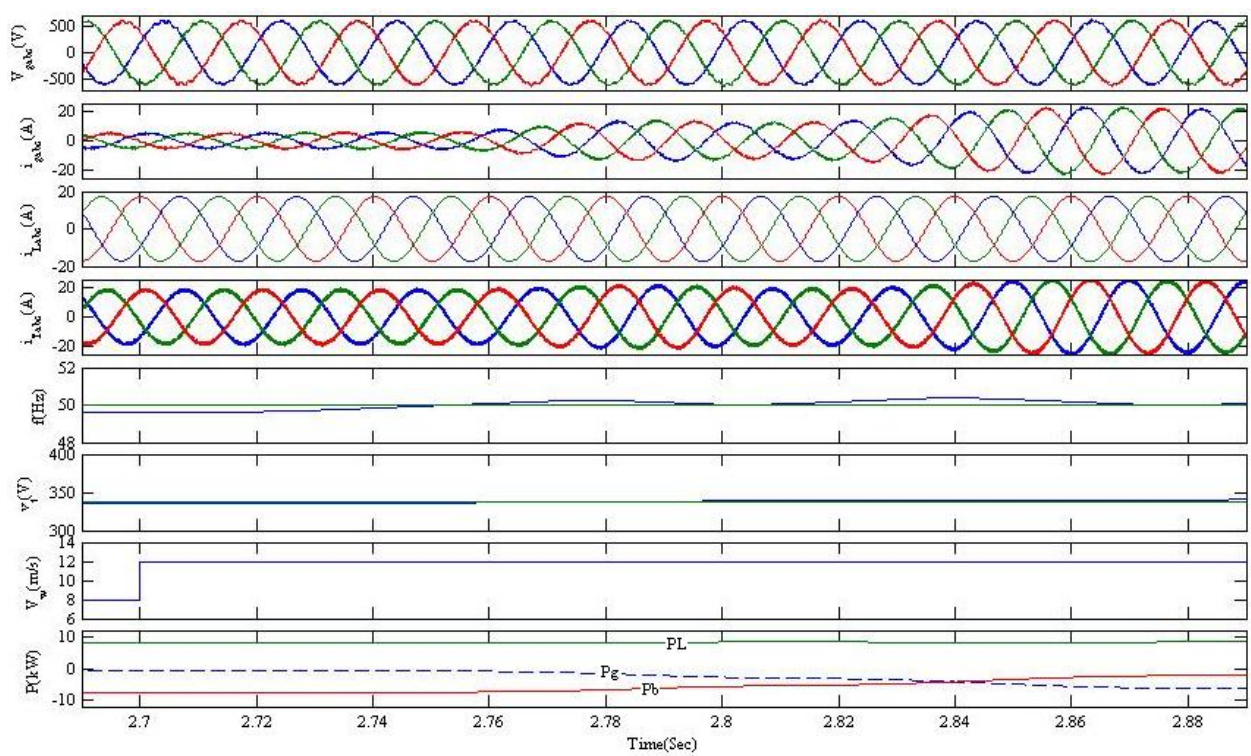

Fig. 6. Performance of VFC without ac capacitors at the terminals of an IAG under increase in wind speed at fixed balanced loads.

constant wind speed of $12 \mathrm{~m} / \mathrm{s}$. Before $2.341 \mathrm{~s}$, a balanced 7.5 $\mathrm{kW}, 0.94$ lagging pf linear load is applied between each phase and neutral terminal connected at the generator bus. A generated power of $7.5 \mathrm{~kW}$ is used to feed the loads, and the battery is in the floating state. At $2.341 \mathrm{~s}$, the loads on phase ' $\mathrm{b}$ ' are switched off and the load becomes unbalanced. It is observed that the three-phase generator currents are balanced although a small reduction in magnitude is momentarily observed in the generated power, due to the action of the voltage PI controller. The reduction in the load is utilized in charging the battery. The load becomes balanced again at $2.42 \mathrm{~s}$. It is observed that the generated voltage and frequency are almost constant during this period. The generator currents remain balanced and unaffected by the load perturbations. The primary windings of the star/delta transformer absorb the zero-sequence load currents during unbalancing conditions.

Fig. 8 shows the performance of the VFC when there are no ac capacitors connected at the terminals of an IAG. These results verify that the VSC can supply the reactive power for IAG excitation and voltage regulation, although there are changes in the VSC ratings. The above results have demonstrated the capabilities of the VFC as a load balancer and a load leveler.

\section{Performance of the VFC with Balanced/unbalanced Non- linear Loads}

Fig. 9 shows the performance of the VFC with ac capacitors connected at the terminals of an IAG as a harmonic eliminator with balanced/unbalanced non-linear loads at a wind speed of $12 \mathrm{~m} / \mathrm{s}$. Three single-phase diode rectifiers with R-L loads are 


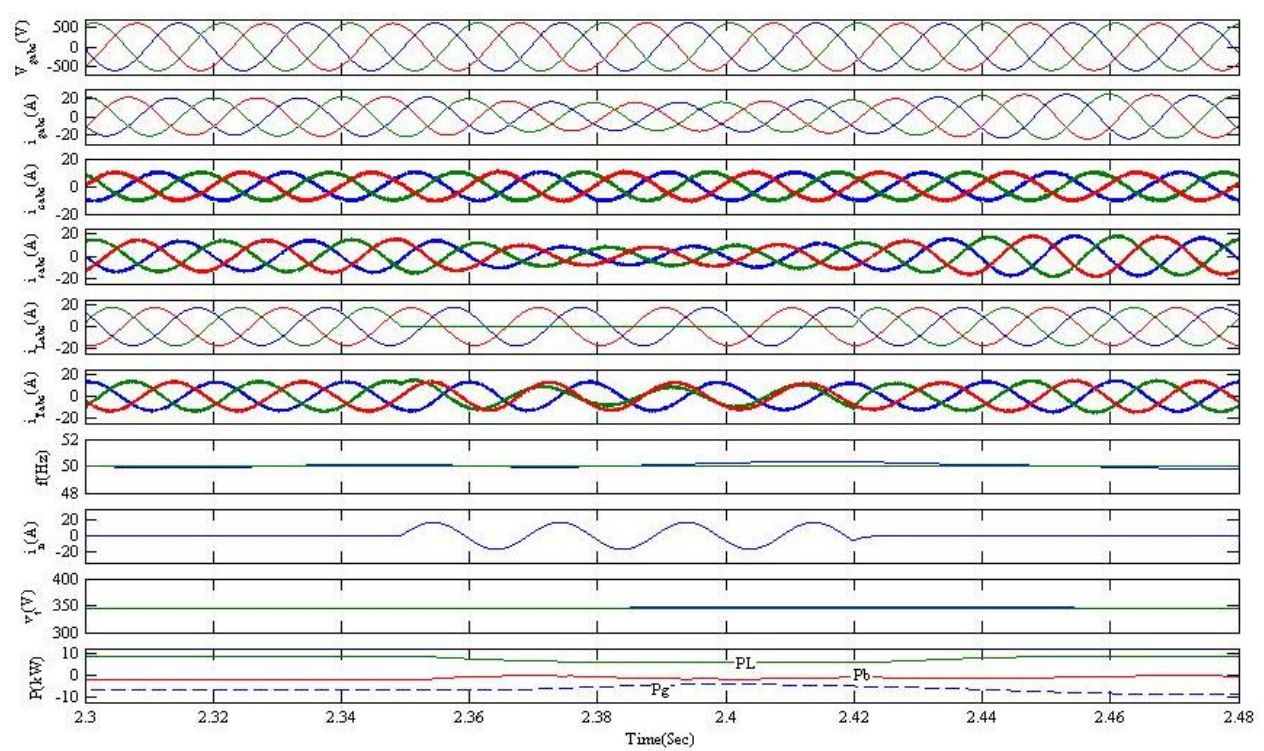

Fig. 7. Performance of VFC with ac capacitors connected at terminals of an IAG at fixed wind speed, balanced/unbalanced linear consumer loads.

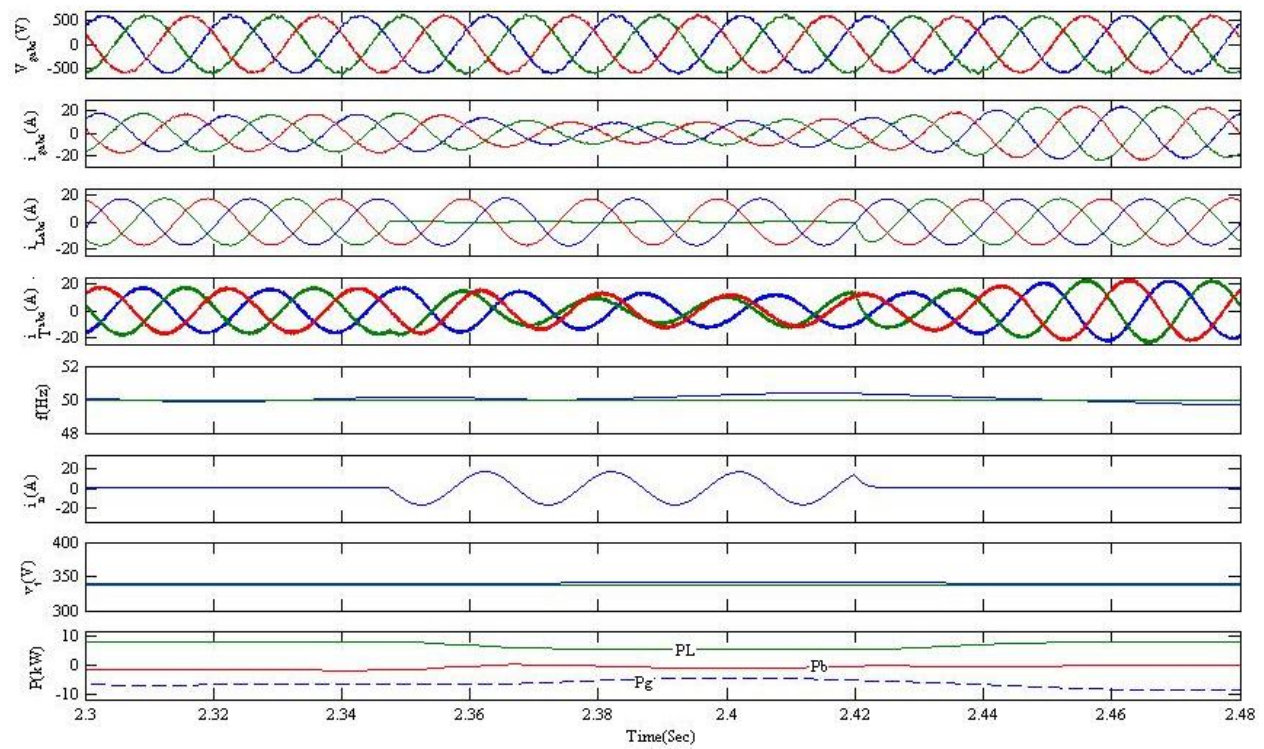

Fig. 8. Performance of VFC without ac capacitors at the terminals of an IAG at fixed wind speed and balanced/unbalanced linear consumer loads.

used as a non-linear load with $\mathrm{L}=90 \mathrm{mH}$ and $\mathrm{R}=20 \Omega$ applied between each phase and neutral terminal. The balanced nonlinear load is connected at all of the three phases till 2.345 $\mathrm{s}$, and it is unbalanced after switching off the phase ' $\mathrm{b}$ ' loads at $2.34 \mathrm{~s}$. The load on phase ' $b$ ' is switched on in again at $2.42 \mathrm{~s}$. Therefore the load becomes balanced again at 2.42 s. It is observed that the generator currents remain balanced and almost sinusoidal during the load perturbations. The VFC maintains the generator voltage and frequency almost constant even under harmonic polluted loads by supplying the additional harmonics and reactive power demands of the load.

Fig. 10 shows the performance of the VFC when ac capacitors are not connected at the terminals of an IAG. Along with a load leveler and a load balancer, the VFC has demonstrated its capabilities as a harmonics eliminator.
The harmonic spectra of the generator voltage, the generator current and the load current of phase "a" are shown in Fig. 11. The total harmonic distortion (THD) of the generator voltage is of the order of $0.44 \%$ and for the generator current, it is $2.92 \%$. Meanwhile, the load current THD is $36.45 \%$. According to the IEEE 519 standard, these THDs of the generator voltage and its current are well within the 5\% limits.

\section{HARDWARE REALIZATION}

An experimental prototype of a $3.7 \mathrm{~kW}, 230 \mathrm{~V}$ three-phase IAG based WECS has been fabricated in the laboratory to verify the performance of the proposed scheme. A Semikron make $25 \mathrm{kVA}$ VSC, a $1 \mathrm{mH}$ interface inductor and a $300 \mathrm{~V}$ battery rack with a $4.5 \mathrm{kVA}$ three phase star/delta transformer are used to realize the VFC. The switching signals for six 


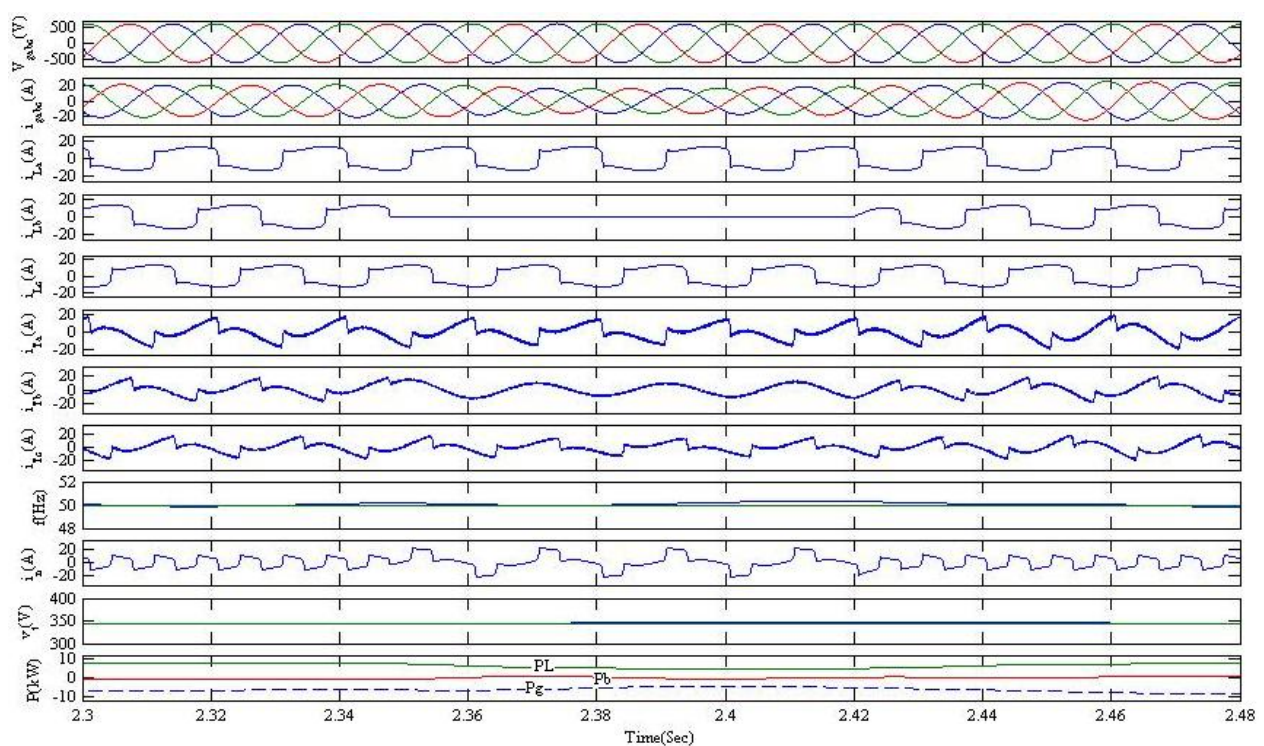

Fig. 9. Performance of VFC with ac capacitors at the terminals of an IAG at fixed wind speed and balanced/unbalanced non-linear consumer loads.

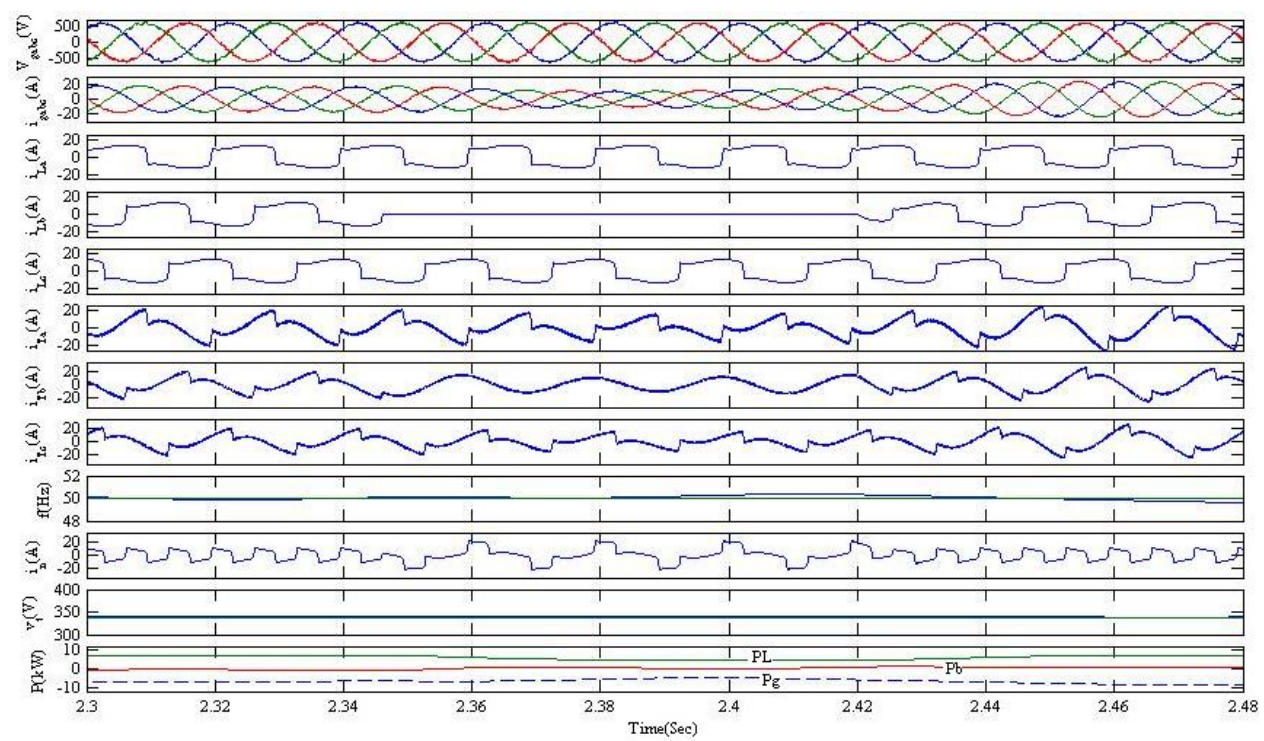

Fig. 10. Performance of VFC without ac capacitors at the terminals of an IAG at fixed wind speed and balanced/unbalanced non-linear consumer loads.

IGBT's (insulated gate bipolar transistor) are generated using a carrier-less PWM controller.

The control algorithm is implemented in real time using a DSP (TMS320F240). The voltage signals are detected using Hall effect voltage sensors (LEM-CV3-1500) and the current signals are detected using Hall effect current sensors (ABB EL50 BB). The signals are sampled in a simultaneous sample time using ADCs. The sampling time is $70 \mu \mathrm{s}$. Three single phase diode rectifiers with resistive-inductive loads are used to realize the non-linear load.

Test results are recorded using a FLUKE 43B power quality analyzer. Fig. 11 shows the various test signals during operation. Figs. 11(a-c) show the line voltage $\left(v_{a b}\right)$ with generator currents $i_{g a}, i_{g b}$, and $i_{g c}$. It is observed that the three phase generator currents are balanced and ripple-free even when the connected consumer load is non-linear in nature. Figs. 11(d-f) show the $v_{a b}$ with the source currents $i_{s a}, i_{s b}$ and $i_{s c}$. Figs. 11(g-i) show the $v_{a b}$ and the consumer three phase load currents $i_{L a}, i_{L b}$ and $i_{L c}$. Figs.12 (a-c) show the $v_{a b}$ with the primary side currents of a star/delta transformer $i_{T a}, i_{T b}$ and $i_{T c}$. The generated power $\left(P_{g}\right)$, the consumer load power $\left(P_{L}\right)$ and the battery charging power $\left(P_{b}\right)$ are recorded in Figs. 12 (d-f). The generator is delivering $3.33 \mathrm{~kW}$, while the load is consuming $2.4 \mathrm{~kW}$ and the difference of the generator and the load power is used to charge the battery $0.92 \mathrm{~kW}$.

\section{CONCLUSION}

A new control algorithm for voltage and frequency control of an IAG has been investigated in an isolated WECS. It has been shown that a three-leg integrated VSC with a battery energy storage system can be a potential candidate as a VFC in isolated direct connected loads. The use of a star/delta 

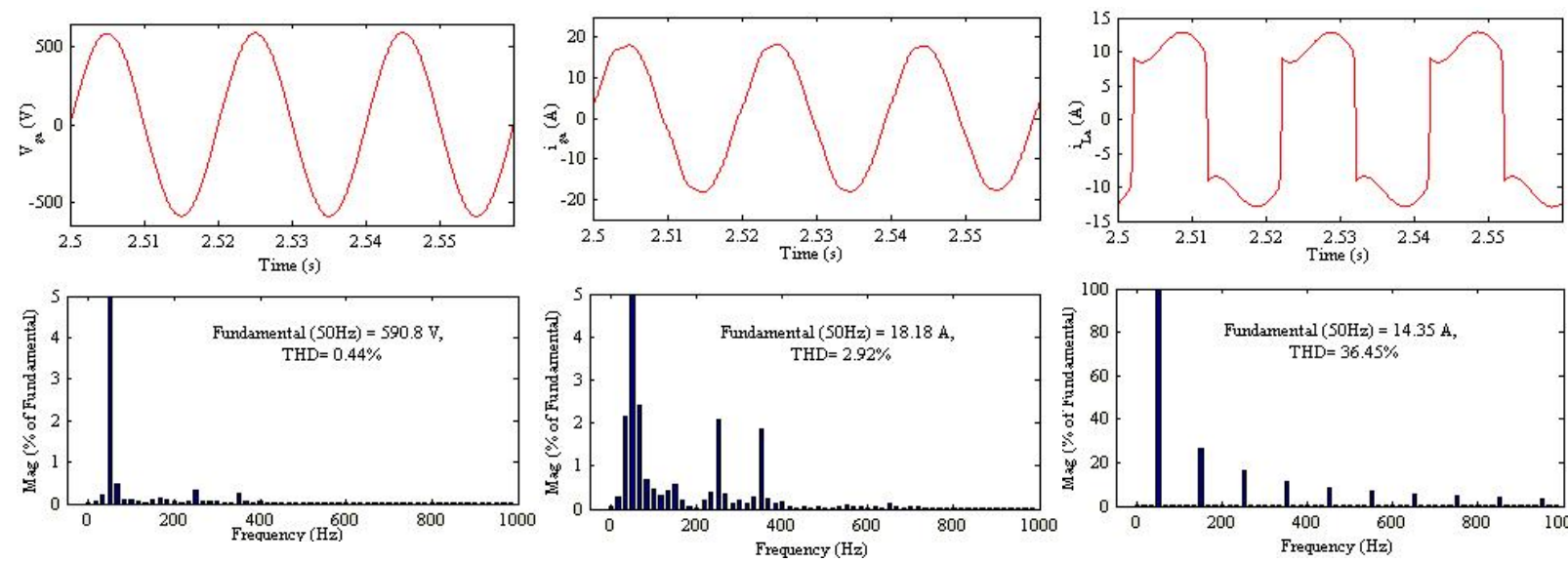

(b)

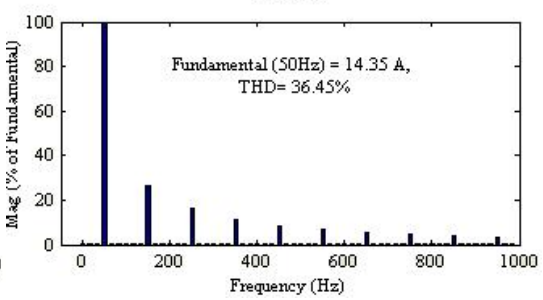

(c)

Fig. 11. Waveforms and harmonics spectra. (a) Generator voltage.(b) Generator current. (c) Load current.

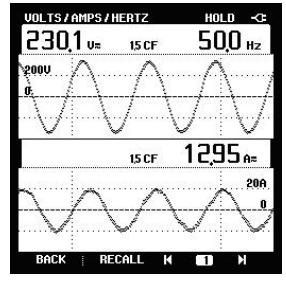

(a)

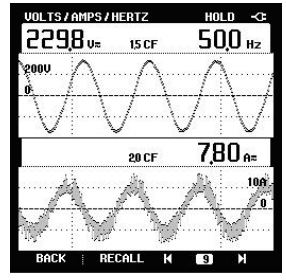

(d)

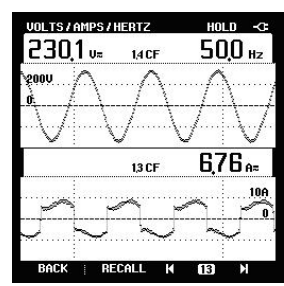

(g)

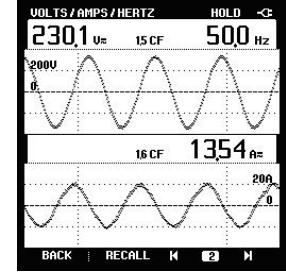

(b)

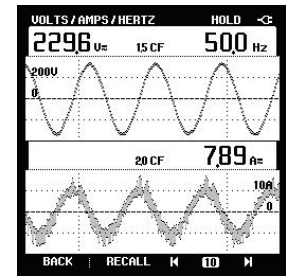

(e)

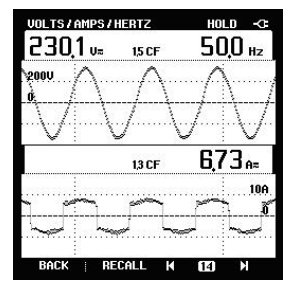

(h)

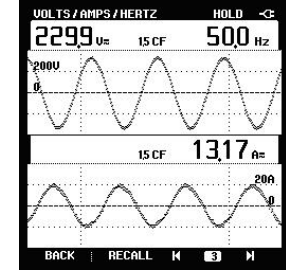

(c)

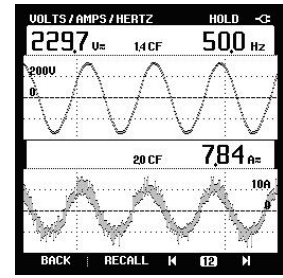

(f)

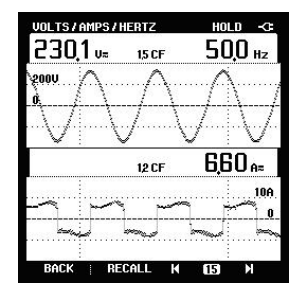

(i)

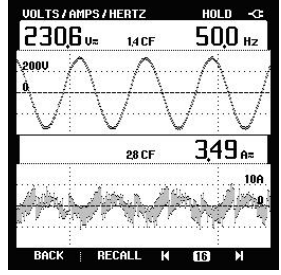

(a)

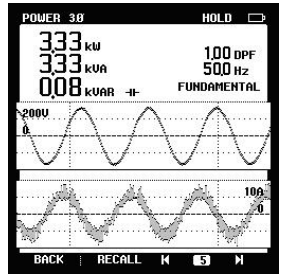

(d)

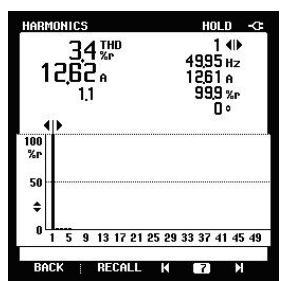

(g)

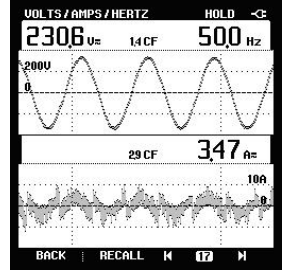

(b)

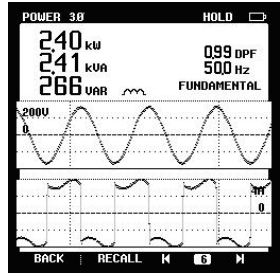

(e)

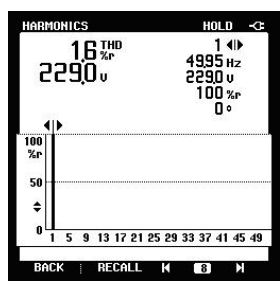

(h)

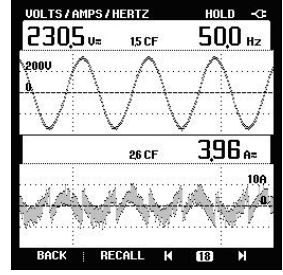

(c)

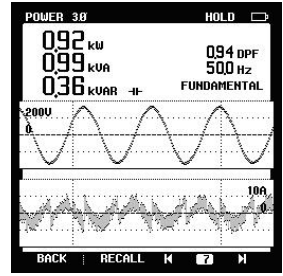

(f)

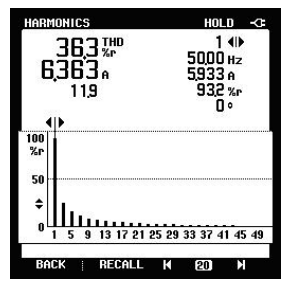

(i)

Fig. 12. Test results of WECS (a) $v_{a b}$ and $i_{g a}$ (b) $v_{a b}$ and $i_{g b}$ (c) $v_{a b}$ and $i_{g c}$ (d) $v_{a b}$ and $i_{s a}$ (e) $v_{a b}$ and $i_{s b}$ (f) $v_{a b}$ and $i_{s c}$ (g) $v_{a b}$ and $i_{L a}$ (h) $v_{a b}$ and $i_{L b}$ (i) $v_{a b}$ and $i_{L c}$.

transformer reduces the VSC volt-ampere ratings by reducing the burden of the zero sequence load currents. A comparative study has been made with an ac capacitor connected at the terminals of an IAG. The obtained results have shown that the presence of the capacitors reduces the VSC voltampere burden. The simulation and experimental results have demonstrated the capabilities of the VFC for power quality improvement.

Fig. 13. Test results of WECS (a) $v_{a b}$ and $i_{v s c A}$ (b) $v_{a b}$ and $i_{v s c B}$ (c) $v_{a b}$ and $i_{v s c C}$ (d) $v_{a b}$ and $P_{g}$ (e) $v_{a b}$ and $P_{L}$ (f) $v_{a b}$ and $P_{b}$ (g) harmonic spectrum of $i_{g A}$ (h) harmonic spectrum of $v_{a b}$ (i) harmonic spectrum of $i_{L a}$.

\section{APPENDIX}

Parameters of the considered system for simulation

IAG data: $7.5 \mathrm{~kW}, 415 \mathrm{~V}, 50 \mathrm{~Hz}$, Y-Connected, 4-pole, $R_{s}=1$ $\Omega, R_{r}=0.77 \Omega, L_{l s}=0.00478 \mathrm{H}, L_{l r}=0.00478 \mathrm{H}, L_{m}=0.334 \mathrm{H}$.

Wind turbine data: $7.5 \mathrm{~kW}, C_{\text {pmax }}=0.48, \Lambda_{m}=8.1$, $C_{1}=0.5176, C_{2}=116, C_{3}=0.4, C_{4}=5, C_{5}=21, C_{6}=0.0068$, $C_{7}=0.008, C_{8}=0.035$.

VFC Parameters: $L_{f}=1 \mathrm{mH}, R_{f}=0.05 \Omega, C_{d c}=7500 \mu F$, $K_{p a}=0.21, K_{i a}=.4, K_{p f}=2000, K_{i f}=150000$. 
Battery parameters: $C_{b}=12000 \mathrm{~F}, R_{b}=10 \mathrm{k} \Omega, R_{s}=0.1 \Omega, V_{o c}$ $=600 \mathrm{~V}$.

Star/delta transformer: Primary windings 239/239/239V.

Secondary windings: $120 / 120 / 120 \mathrm{~V}$.

Excitation Capacitors: 7.5kVAR, $415 \mathrm{~V}, 50 \mathrm{~Hz}$.

VSC Ratings (with excitation capacitors): $8.2 \mathrm{kVA}$

VSC Ratings (without excitation capaciotrs): $14.2 \mathrm{kVA}$.

\section{REFERENCES}

[1] M. Kaltschmitt, W.Streicher and A. Wiese, Renewable Energy, Technology and Environment, Economics, Springer-Verlag Berlin Heidelberg, 2007.

[2] Mukund R. Patel, Wind and SolarPower Systems, CRC Press, LLC, 2000.

[3] G.K. Kasal and B. Singh, "Decoupled voltage and frequency controller for isolated asynchronous generators feeding three-phase four-wire loads," IEEE Trans. Power Delivery, Vol. 23, No.2, pp. 966 - 973, Apr. 2008.

[4] R.M. Hillowala and A.M. Sharaf, "A rule based fuzzy logic controller for a PWM inverter in a stand -alone wind energy conversion scheme," IEEE Trans. Ind. Appl., Vol. 32, No. 1, pp. 57-65, Jan./Feb. 1996.

[5] G.K. Kasal, B. Singh, A. Chandra and K. Al-Haddad, "Voltage and frequency control with neutral current compensation in an isolated wind energy conversion system," in Proc. IECON 2008, pp. 2259 - 2264, 2008.

[6] C.V Nayar and J.H. Bundell, "Output power controller for a wind-driven induction generator," IEEE Trans. on Aerospace and Electronic Systems, Vol. AES-23, No. 3, pp. 388 - 401, May 1987.

[7] Bhim Singh and G. Kasal, "Battery energy storage system based controller for a wind turbine driven isolated asynchronous generator," Journal of Power Electronics, Vol. 8, No. 1, pp.81-90, Jan. 2008.

[8] U.K. Rao, M.K. Mishra and A. Ghosh, "Control strategies for load compensation using instantaneous symmetrical component theory under different supply voltages," IEEE Trans. Power Delivery, Vol. 23, No. 4 pp.2310- 2317, Oct. 2008.

[9] H. Akagi, E.H. Watanabe and M. Aredes, Instantaneous Power Theory and Applications to Power Conditioning, Wiley-Inter-science, IEEE Press, 2007.
[10] P. Verdelho and G.D. Marques, "Active power filter control circuit with phase locked loop phase angle determination," in Proc. PEMC'98, Sep.8-10, 1998.

[11] Z.M. Salameh, M.A. Casacca and W.A. Lynch, "A mathematical model for lead acid batteries," IEEE Trans. Energy Conversion, Vol. 7, No. 1, pp. 93-97, Mar. 1992.

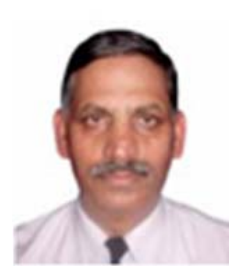

Bhim Singh was born in Rahamapur, India, in 1956 He received his B.E. from the University of Roorkee, Roorkee, India, in 1977 and his M.Tech and Ph.D. from the Indian Institute of Technology (IIT) Delhi, New Delhi, India, in 1979 and 1983, respectively. In 1983, he joined the Department of Electrical Engineering, University of Roorkee, as a Lecturer, and in 1988 he became a Reader. In December 1990, he joined the Department of Electrical Engineering, IIT Delhi, as an Assistant Professor. He became an Associate Professor in 1994 and a Professor in 1997. His areas of interest include power electronics, electrical machines and drives, active filters, FACTS, HVDC and power quality. He is a Fellow of the Indian National Academy of Engineering (INAE), the National Science Academy (FNSc), the Institution of Engineers (India) (IE(I)), and the Institution of Electronics and Telecommunication Engineers (IETE). $\mathrm{He}$ is also a life member of the Indian Society for Technical Education (ISTE), the System Society of India (SSI), and the National Institution of Quality and Reliability (NIQR). In addition he is a Fellow of the Institute of Electrical and Electronics Engineers (IEEE).

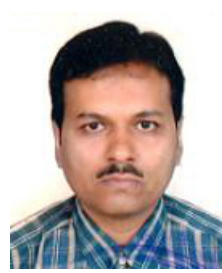

Shailendra Sharma was born in Indore, India, in 1972. $\mathrm{He}$ received his M.E. in Electrical Engineering with specialization in power electronics in 2004 from the Shri Govindram Seksaria Institute of Technology and Science, Indore, India. He has five years of industrial experience as an erection and commissioning engineer. $\mathrm{He}$ joined the Department of Electrical Engineering, Shri GSITS, Indore in 2004 as a Lecturer. Presently, he is pursuing research at Indian Institute of Technology, Delhi, India, under the Quality Improvement Programme. His fields of interest include power electronics, drives, power quality, and renewable energy. He is Associate Member of the Institution of Engineers India. 